\title{
Effect of Coating and Welding Wire Composition on AHSS GMA Welds
}

\author{
The roles of galvanized iron coating and filler material on weld strength were \\ investigated for different weld configurations using the DIC technique
}

\author{
BY A. R. H. MIDAWI, S. KISTAMPALLY, AND E. BIRO
}

\begin{abstract}
Advanced high-strength steels (AHSS) such as complexphase (CP) and high-formability (HF) steel offer weightsaving advantages for automotive applications such as chassis and frame applications. To prevent material oxidation, materials are often galvanized to protect the substrate from corrosion. However, the weldability of coated AHSS becomes challenging due to the trapping of zinc in the weld molten pool, which could lead to weld defects such as porosity and liquid metal embrittlement cracks. This work focused on the weldability of AHSS (CP800 and 980HF) using the gas metal arc welding process. The roles of both galvanized iron coating and filler material on weld strength were investigated. The welds were performed using two different filler materials: a low-strength filler (ER70S-6) and a high-strength filler (ERIO0S-6) material. In addition, two different joint configurations were studied: lap joints and butt joints. The results showed that the butt joint had a higher strength compared to the lap joints. Furthermore, the strength of the butt joint overmatched the base material strength in all of the tested materials (both in galvanized and uncoated). In general, lap joint strength undermatched the base material strength, which was attributed to the rotation during tensile testing that induced unaccounted bending stress on the lap joint, while using a higherstrength welding wire improved the tensile strength material in the lap joint configuration. The hardness profiles in the 980HF steel also showed a significant hardness mismatch due to the formation of a fully martensitic microstructure in the heat-affected zone, which led to suppressing the deformation across the lap joint.
\end{abstract}

\section{KEYWORDS}

- Advanced High-Strength Steel (AHSS)

- Gas Metal Arc Welding (GMAW)

- Digital Image Correlation - Tensile Strength

- Lap Shear Test • Butt Joint • Filler Material Strength

\section{Introduction}

The need to decrease the curb weight of automobiles to reduce $\mathrm{CO}_{2}$ emission and meet greenhouse gas emission regulations encouraged the automotive industry to use advanced high-strength steel (AHSS) for frame applications (Refs. 1, 2). This allows thinner gauges of steel to be used to manufacture automotive parts, reducing part weight and improving vehicle fuel economy while maintaining or increasing vehicle safety (Refs. 2-4). To join steels in an automotive structure, welding processes such as laser beam welding (LBW) and resistance spot welding (RSW) are the most frequently used (Ref. 5). However, due to the thickness of the sheets used for frame applications, gas metal arc welding (GMAW) is often used (Ref. 6). When AHSS is welded, the resultant weldments can exhibit heterogeneous properties where the hardness will vary greatly across the weld zone. This is due to the complex chemical composition and microstructures of the AHSS resulting from the local heating cycles associated with welding (Ref. 7). After welding, the supercritical heat-affected zone (SCHAZ) adjacent to the fusion zone (FZ) can form martensite, resulting in very high local hardness. Conversely, away from the FZ, where the peak temperature reached during welding does not exceed the $\mathrm{Ac}_{1}$ temperature of the steel, any martensite in the base material will temper, resulting in a local hardness drop below that of the base material, known as heat-affected zone (HAZ) softening (Refs. 7, 8). Variation in local properties can control the failure location of the weld joint during tensile testing, where the exact failure location depends on the relative strength of the various areas in the weld zone (Refs. 9, 10). The galvanized coating on AHSS is important to protect the material surface from corrosion. However, the zinc coating adds complexity to the welding process. This is due to several factors, including the difficulty of achieving a stable arc, increasing spatter, and increasing porosity in the weld metal (Refs. 11-13). All of these issues relate to the low vaporization temperature of $\mathrm{Zn}\left(907^{\circ} \mathrm{C}\right)$, which is much lower than the melting temperature of steel $\left(1500^{\circ} \mathrm{C}\right)$ (Ref. 14). To avoid these issues in the zinc-coated steel, several solutions have been reported in the literature, such as controlling the welding current and torch position (Ref. 12), using a flux cored welding wire specifically developed for GMAW of zinc-coated steels (Ref. 13), or leaving a small gap (0.1-0.3 $\mathrm{mm}$ ) between the lap-joined sheet to allow the zinc fume to 

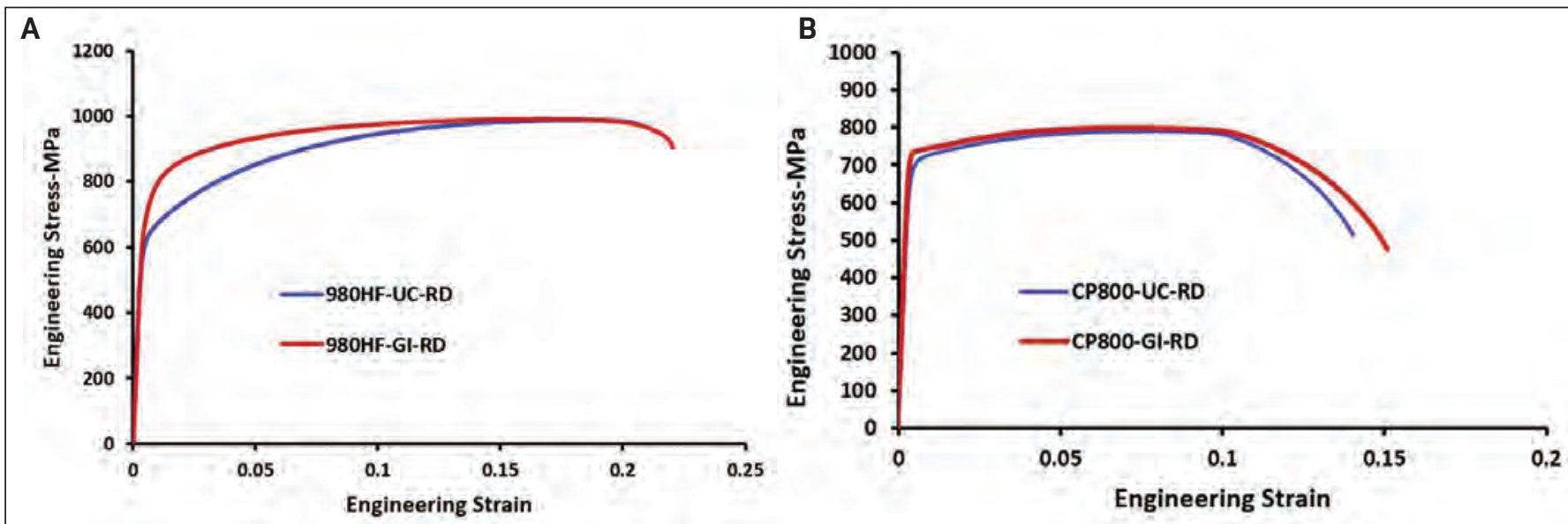

Fig. 1 - Engineering stress-strain curves for both materials: A - 980HF; B - CP800.

escape during welding (Ref. 11). With GMAW, low-strength welds are tolerant of small amounts of internal porosity (Refs. 10, 13, 15). However, in higher-strength materials, it will be more important for welds to remain pore free to maintain weld strength because the overmatching between the FZ and base material will be much less than observed in lower-strength steels (Ref. 10).

To evaluate GMAW joint strength in automotive applications, tensile lap shear tests and butt joint tensile tests are usually performed to measure the strength under different loading and failure scenarios. Due to the geometry of the lap joint, there is eccentric loading during lap shear testing and the lap joint rotates, applying a bending moment, which is not accounted for during standard strength testing methods (Ref. 10). In the butt joint configuration, the loading condition is symmetric, and the joint does not rotate during testing. Ono et al. (Ref. 16) investigated the static and fatigue strength for various uncoated high-strength steel sheets. The study focused on the strength of laser beam welded lap joints, which were compared to those of spot welds in the same material. The study proposed a relation to estimate the strength and fracture position of the laser lap joint. The suggested formula considers the angle of the rotation of the lap joint, the sheet thickness, the weld width, and the hardness of the weld. However, in the study by Ono et al., the material was not coated and no filler material was used as LBW and RSW were studied.

Kapustka et al. (Ref. 17) investigated the effect of the cooling rate, material prestrain, and filler metal composition on the microstructure and mechanical properties of GMA welds in dual-phase (DP) and transformation-inducedplasticity (TRIP) steels. The welds were made in two different configurations: lap and butt joints. The study reported that filler metal strength did not affect the static and dynamic tensile properties of TRIP780 in both weld configurations, while the lap joint in DP780 had a higher strength than when welded with the high-strength welding wire. Kapustka et al. reported that increasing the cooling rate by reducing heat input (using a short-circuit transfer mode) promoted porosity and led to a significant loss in joint efficiency. Therefore, using higher heat input (low cooling rate) will help $\mathrm{Zn}$ bubbles escape from the molten pool before solidifi- cation. Ahsan et al. (Ref. 1) investigated the mechanism of porosity formation, growth, and escape in GMA welds by controlling the heat input parameters. The porosity formation was explained using the viscosity of the weld pool and the vapor pressure of the zinc. However, the study results agreed with those of Kapustka et al. (Ref. 17), which showed pores unable to rise from the weld pool, leaving small pores near the weld root, although in small numbers these small pores will not affect the mechanical performance. A highheat-input (more than $350 \mathrm{~J} / \mathrm{mm}$ ) Zn vapor will grow and escape the molten pool. This being said, a high heat input has side effects such as inducing high deformation due to the thermal residual stresses and may require the use of low welding speed, which will reduce productivity (Refs. 18, 19).

In this work, optimized standard industrial parameters with relatively low heat input were used to study the effect of filler metal composition and $\mathrm{Zn}$ coating on joint performance. A standard robotic GMAW technique was used to join two AHSS alloys: a complex phase (CP800) and high formability (980HF). The material was examined in two different conditions: bare surface and galvanized iron (GI) zinc coated. Two different joint configurations were studied: lap and butt joints. Microstructural analysis and hardness measurements were performed to understand the local variation in the mechanical properties of the failure location. Strain developed during tensile testing was mapped using digital image correlation (DIC) to evaluate the strain distribution in the local zones across the weld. The DIC results were correlated with the hardness results to understand the effect of filler material strength and $\mathrm{Zn}$ coating on the joint performance. Implementing the results of this project was the first step to integrating heavy ( $>2$ $\mathrm{mm}$ ) AHSS into frame applications. Increasing the use of AHSS in frame applications will allow thinner materials to be used for automotive designs, thus decreasing vehicle weight and reducing environmental impact.

\section{Experimental Setup}

In this work, two materials were investigated: HR-CP800 and $980 \mathrm{HF}$. Both materials were supplied in uncoated conditions and GI coated on both sides. The coating thickness for 

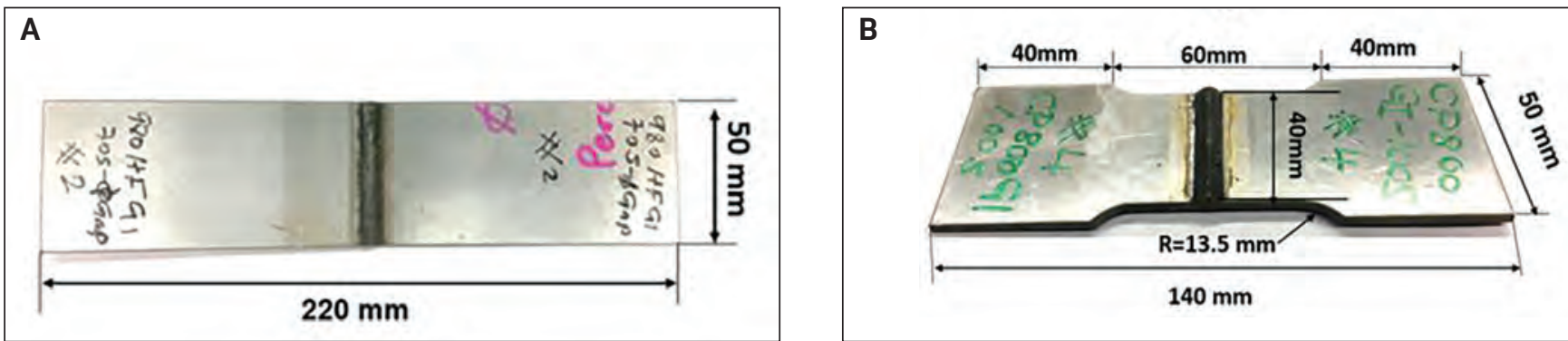

Fig. 2 - Tensile test coupons geometry: A - Lap joint; B - butt joint.

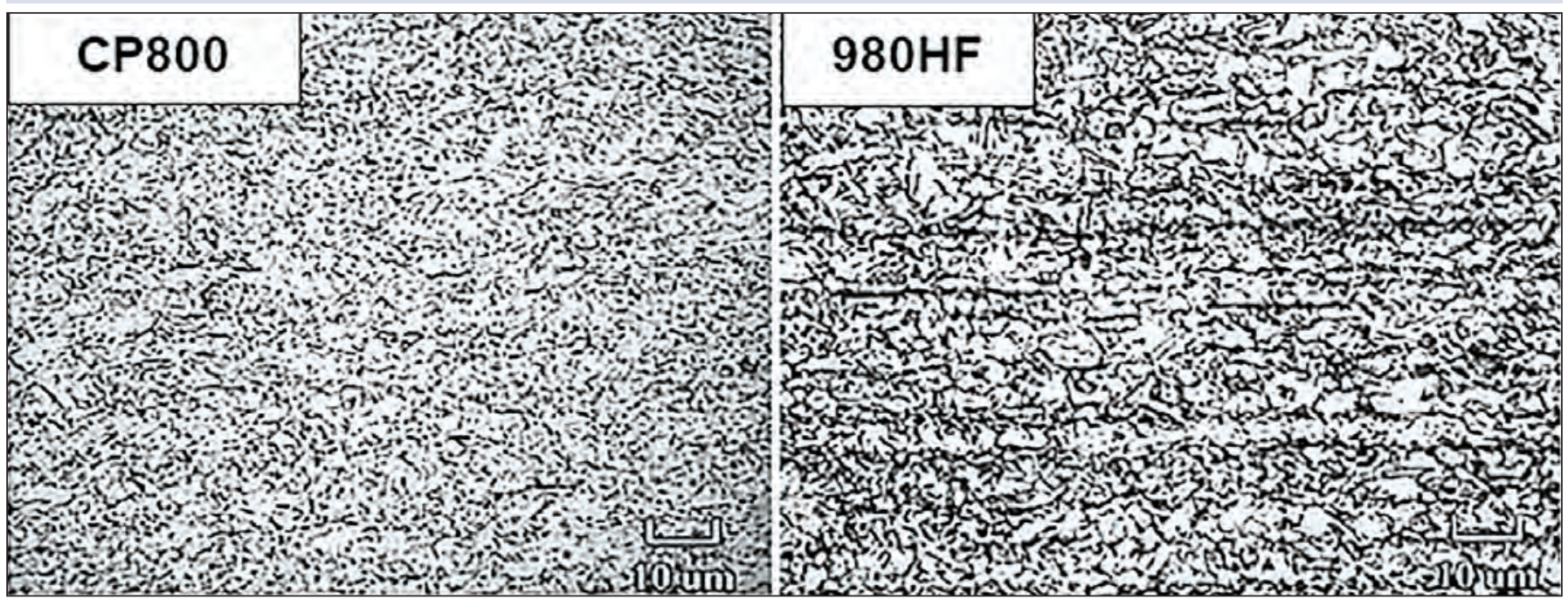

Fig. 3-Optical micrographs show the base materials' microstructures.

$980 \mathrm{HF}$ sheets was $8.5 \pm 0.7 \mu \mathrm{m}$, while the CP800 sheet's coating thickness was $13 \pm 2.5 \mu \mathrm{m}$. The chemical compositions, along with the carbon equivalent, of the base materials are listed in Table 1 . The carbon equivalent was calculated using Yurioka's formula (Ref. 20). DIC tensile testing was performed for both materials' coated and uncoated sheets to determine the mechanical properties for the base material. The engineering stress-strain curves are shown in Fig. 1, and to compare the coated vs. uncoated properties, the mechanical properties are listed in Table 2.

Robotic GMAW was used to join the sheets. The specimen size used in this study was $300 \times 300 \mathrm{~mm}(12 \times 12$ in.). Welding was performed parallel to the rolling direction of the base material. Welds were made in both the butt and lap joint configurations. The overlap distance used for the lap joint was $25 \mathrm{~mm}$ (1 in.). The butt joint was welded in the flat position, and a small gap was left between the sheets to allow the $\mathrm{Zn}$ fume to escape. The lap joint was welded using a 30-deg torch angle. In both weld configurations, the contact tip working distance was about $12 \mathrm{~mm}$. To understand the role of FZ strength on weld mechanical properties, two different consumables were used, a low-strength welding wire (ER70S-6) and a high-strength welding wire (ER100S-6) (Ref. 21). The details for the welding parameters and consumables are listed in Table 3. It should be noted that all welds were made using standard industrial parameters that were chosen based on manufacturing robustness.

\section{Sample Preparation}

Samples were cut from the welded sheets (using a waterjet) to perform the mechanical testing (lap shear and tensile test) as well as to characterize the microstructure and perform the hardness test in different zones through the weld joint. Standard uniaxial tensile and lap shear tests were performed at room temperature using an initial displacement rate of 1 $\mathrm{mm} / \mathrm{min}$. Testing was carried out on an MTS frame with a maximum capacity of $100 \mathrm{kN}$. Tensile samples were prepared to the dimensions shown in Fig. 2 to match the testing suggested by the Auto/Steel Partnership (Ref. 22) and the work done by Min Kuo (Ref. 23) to be comparable to previous studies conducted on these materials. During testing, sample elongation was measured using a noncontact DIC measurement technique. This enabled the measurement of elongation across the gauge length. Furthermore, the DIC technique was also able to provide full-field strain measurement and mapping strain distribution in two- or three-dimensions. To use the DIC technique, samples were prepared by applying a random speckle pattern to their surface by painting the sample with white paint followed by speckling them with black spray paint. To reduce load eccentricity during lap shear tensile testing, the test coupons were shimmed.

To analyze the weld microstructure and hardness, cross sections of the welds were cut and hot mounted in conductive bakelite. The samples were prepared for metallographic examination according to ASTM E3-11, Standard Guide for 
Table 1-Chemical Composition and Carbon Equivalent for Base Materials

\begin{tabular}{ccccc} 
Material & CP800-UC & CP800-Gl & 980HF-UC & 980HF-Gl \\
\hline $\mathrm{C}$ & 0.09 & 0.08 & 0.20 & 0.23 \\
$\mathrm{Mn}$ & 1.19 & 1.19 & 2.14 & 1.97 \\
$\mathrm{Si}$ & 0.16 & 0.17 & 1.02 & $\mathrm{Al}, \mathrm{Cr}$ \\
Other Elements & $\mathrm{Cr}, \mathrm{Ti}, \mathrm{Ni}, \mathrm{B}, \mathrm{Al}$ & $\mathrm{Cr}, \mathrm{Ti}, \mathrm{Ni}, \mathrm{B}, \mathrm{Al}$ & $\mathrm{Al}, \mathrm{Cr}, \mathrm{V}, \mathrm{B}$ \\
$\mathrm{C}_{\text {eq }}$ & 0.345 & 0.337 & 0.622 \\
\hline
\end{tabular}

Table 2 - The Mechanical Properties for the Base Materials

\begin{tabular}{ccccc} 
Material & CP800-UC & CP800-Gl & 980HF-UC & 980HF-GI \\
\hline Thickness-mm & 2.4 & 2.5 & 1.2 & 615 \\
YS-MPa & 722 & 735 & 967 & 960 \\
UTS-MPa & 795 & 802 & 20.6 & 998 \\
Elongation-\% & 14.0 & 15.0 & 22.0 \\
\hline
\end{tabular}

Table 3 - Welding Parameters for Butt and Lap Joints

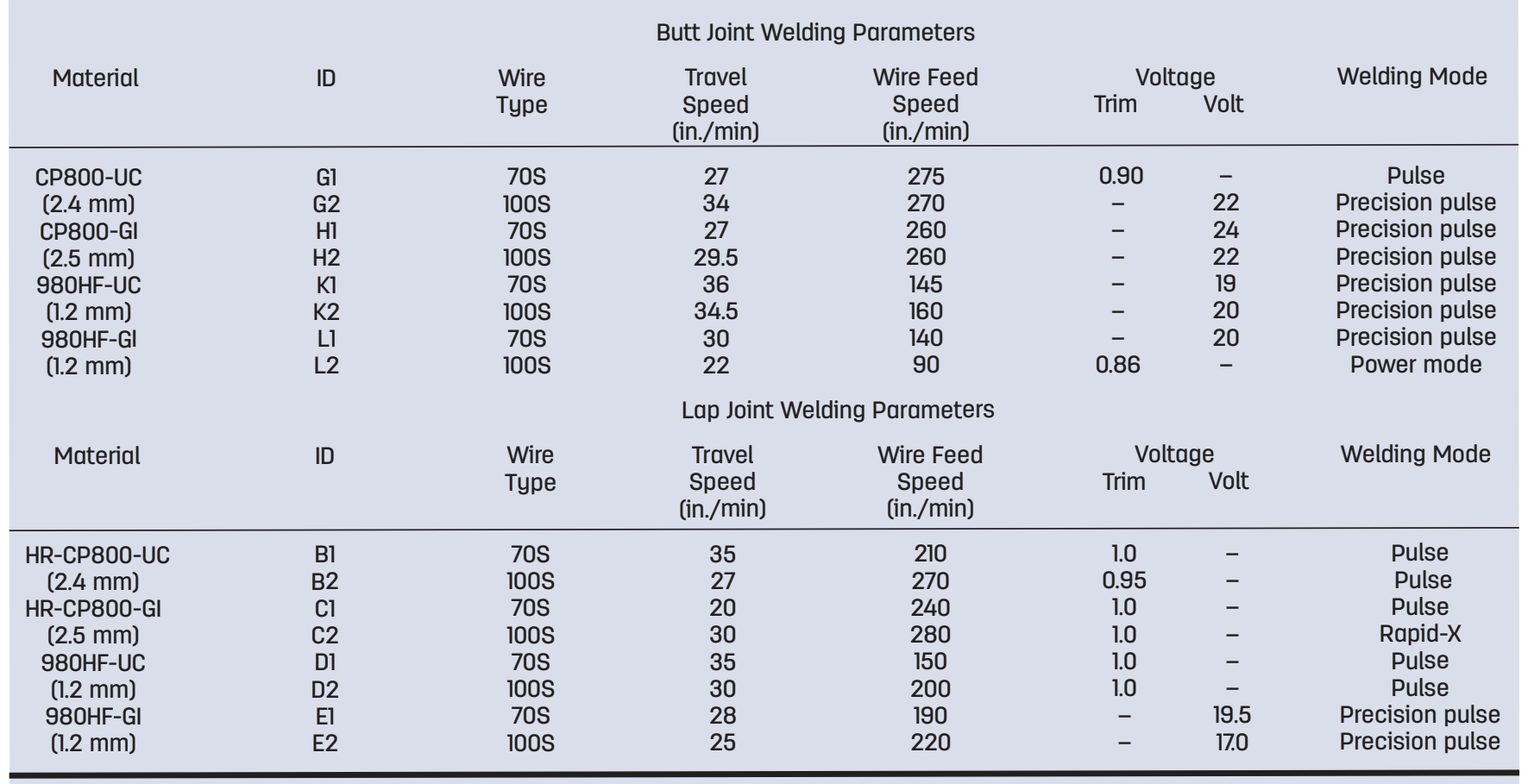

the Preparation of Metallographic Specimens (Ref. 24). The mounted samples were ground using silica grit paper starting with 120, 240, 320, 400, 600, and 1200 sizes. Automated diamond polishing was used to ensure a high-quality surface finish with different particle sizes starting at 9, 3, and then $1 \mu \mathrm{m}$. After polishing, the samples were etched using a $5 \%$ Nital solution for $5 \mathrm{~s}$ and rinsed with water followed by alcohol. The microhardness was measured using an automated Vickers microhardness tester (Clemex Hardness Tester). The Vickers hardness tests were performed according to ASTM E384, Standard Test Method for Microindentation Hardness of Materials (Ref. 25). The hardness indentation load was $0.5 \mathrm{kgf}$, and the spacing between the indents was at least three times the indent diagonal to avoid interac- tion of adjacent plastic deformation fields. The dwell time was set to be $10 \mathrm{~s}$.

\section{Results and Discussion}

\section{Base Material Microstructure and Hardness}

The microstructure of the base metal (BM) is shown in Fig. 3. The complex-phase steel CP800 BM exhibited a very fine microstructure consisting of ferrite, bainite, and martensite. The hardness of the base material was 255 and $248 \mathrm{HV}_{0.5}$ for the uncoated and GI-coated CP800 sheets, respectively. Figure 3 also shows the $980 \mathrm{HF}$ microstructure, which contains fer- 


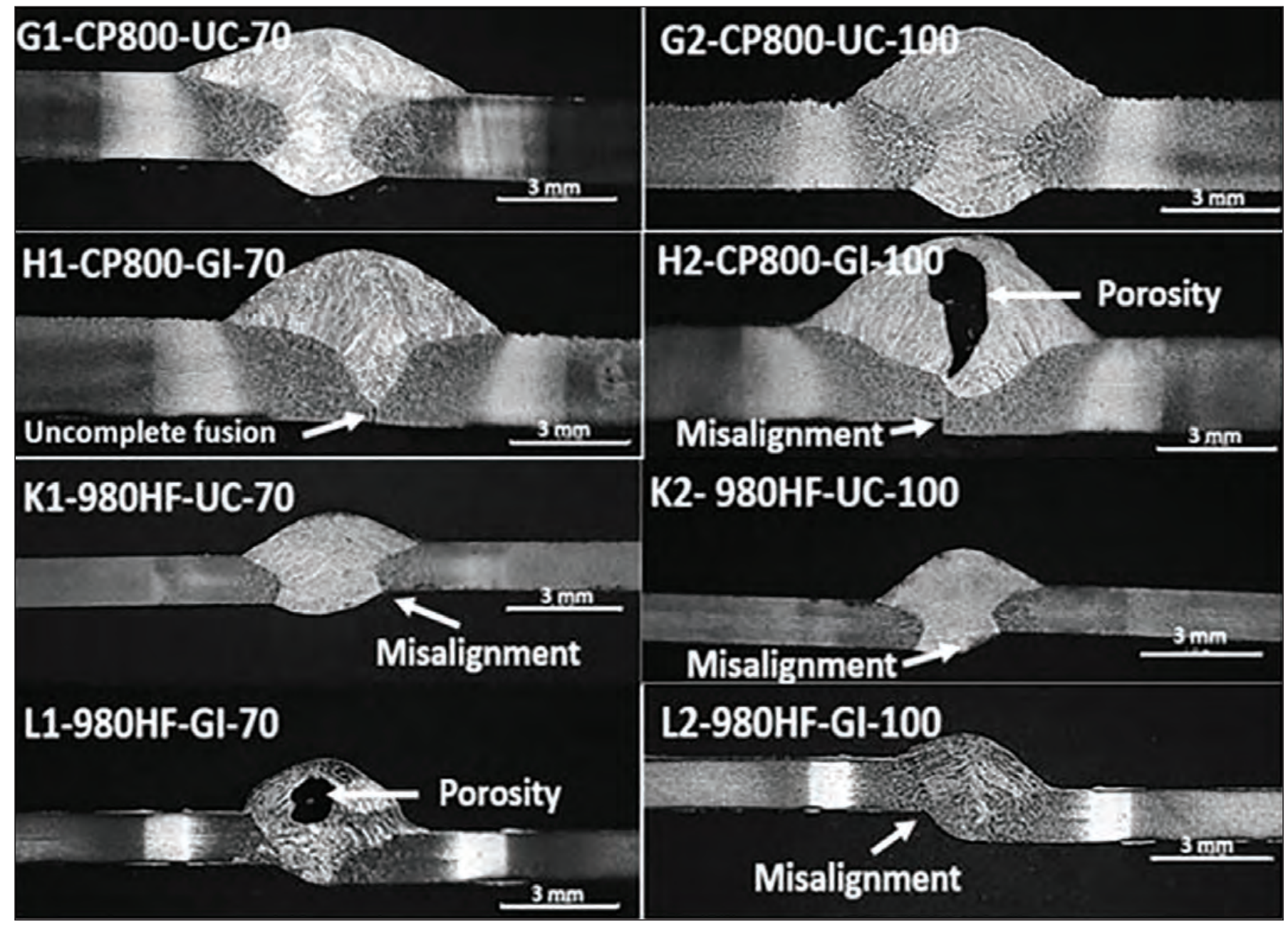

Fig. 4 - The cross section shows the macrostructure for butt joints.

rite, bainite, and some martensite. It should be noted that this structure is heavily banded due to the rolling process that is usually involved to produce AHSS sheets. The BM hardness was 305 and $310 \mathrm{HV}_{0.5}$ for the uncoated and GI-coated $980 \mathrm{HF}$ sheets, respectively.

\section{Macro- and Microstructure for Butt Joints}

The macrographs in Fig. 4 show the cross section of the butt joints for both materials in the galvanized and uncoated conditions. It can be seen that some of the GI-coated welds exhibited porosity (the most severe pore has been shown here), although it should be noted that this was not universal. Cluster porosity has been reported in the literature. Cluster porosity in amounts up to $10 \%$ had no significant effect on joint strength, and that is discussed in the Mechanical Testing section (Ref. 26). The porosity did not follow trends with welding wire strength or material. Misalignment could also be observed in all $980 \mathrm{HF}$ welded samples. Finally, incomplete fusion was also observed in the CP800 GI-coated sheets.

\section{Weld Metal/HAZ Microstructure}

The weld metal microstructure is shown in Fig. 5 for all welding conditions. The use of the high-strength welding wire
(ER100S-6) refined the weld structure and increased the volume fraction of acicular ferrite. However, it should be noted that these changes may not be due to a change in filler material alone because different welding parameters were used for welds made using the different welding wires. Therefore, it is unclear which of these two factors had a stronger influence on the change in structure. The impact of this on properties is discussed in more detail in the next section. It was observed that the FZ microstructure of the uncoated materials differed from that of the GI-coated materials. For example, the $980 \mathrm{HF}$ uncoated samples had a fine microstructure, composed of a mixture of acicular ferrite, martensite, and bainite when welded with both welding wires. Conversely, the FZ microstructures of the GI-coated $980 \mathrm{HF}$ sheets welded with both welding wires were fully martensitic. It is believed that this was due to the differences in the base material compositions of each material (see Table 1). The composition and carbon equivalent will strongly influence the FZ and $\mathrm{HAZ}$ microstructures.

The microstructure of the coarse-grained HAZ (CGHAZ) was very heavily influenced by the base material microstructure and chemical composition of the base material and not affected by welding wire type (Fig. 6). The CGHAZ of the CP800 was a mixture of upper bainite and some Widmanstätten ferrite. The volume fraction and the morphology of the upper bainite and Widmanstätten ferrite varied based on the chemi- 


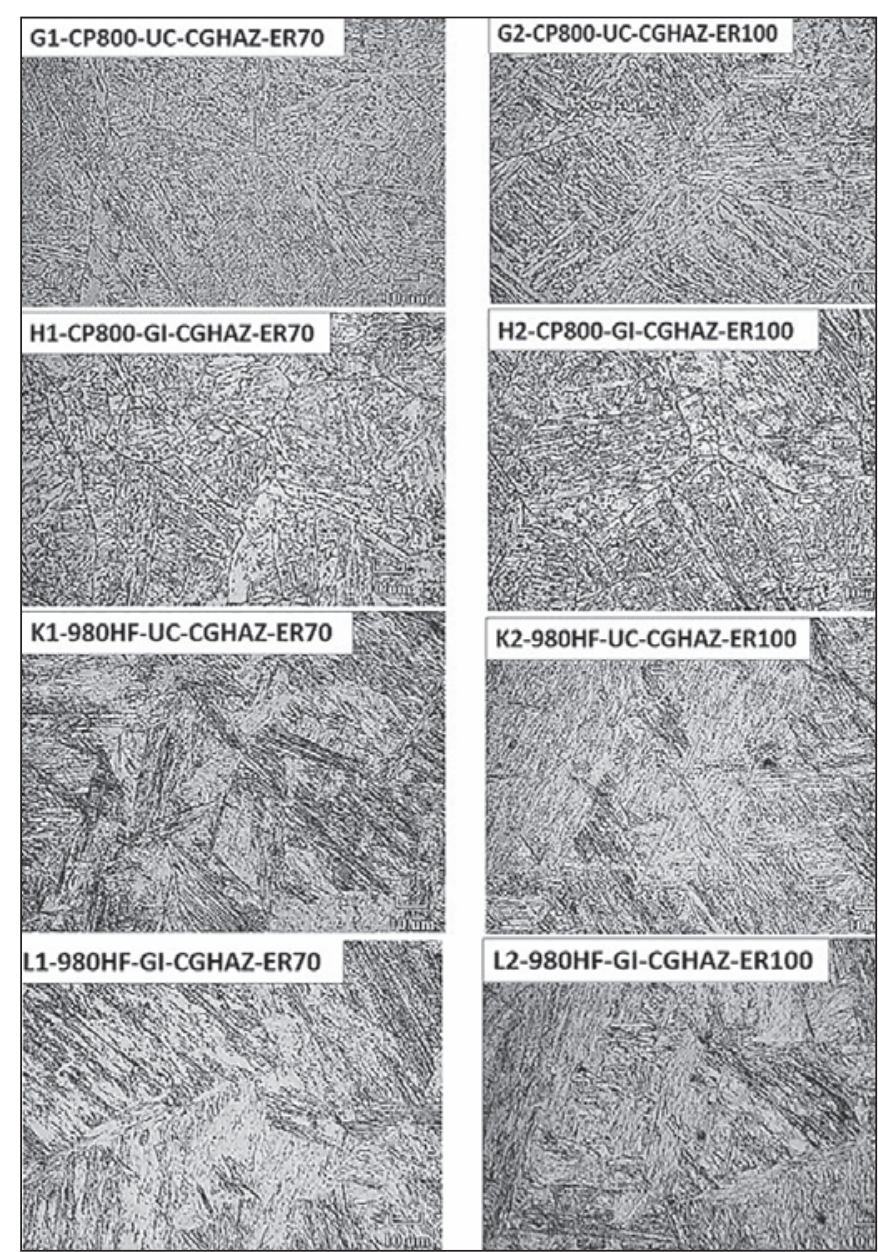

Fig. 5- Optical micrographs show the weld metal for each condition.

cal composition of the base material (GI coated vs. uncoated). Due to the high carbon equivalent of the $980 \mathrm{HF}$ base material, the microstructure of the CGHAZ was fully martensitic, which led to an increase in the hardness and strength mismatch and controlled the failure location.

\section{Hardness Maps across the Butt Joint}

Hardness was measured for all welds using a hardness mapping system. As one would expect, the FZ of welds made using ER100S-6 were harder than those made using the lowerstrength ER70S-6 welding wire (Fig. 7). Welding wire and base material composition had a large influence on FZ hardness. For example, the average hardness of the FZ of the UC-CP800 welded with ER100S- 6 was $248 \mathrm{HV}_{0.5}$, whereas the hardness of the GI-coated CP800 welded with the same welding wire was $275 \mathrm{HV}_{0.5}$. It is also interesting to note that the HAZ hardness of all CP800 welds softened below that of the base material. For example, the minimum hardness in the HAZ of the UCCP800 welded with the ER70S- 6 welding wire was $230 \mathrm{HV}_{0.5}$, whereas it had a BM hardness of $255 \mathrm{HV}_{0.5}$. HAZ softening was not seen in all welds in the $980 \mathrm{HF}$. The hardness maps from all the welds may be seen in Fig. 7, and the data are summarized in Table 4.

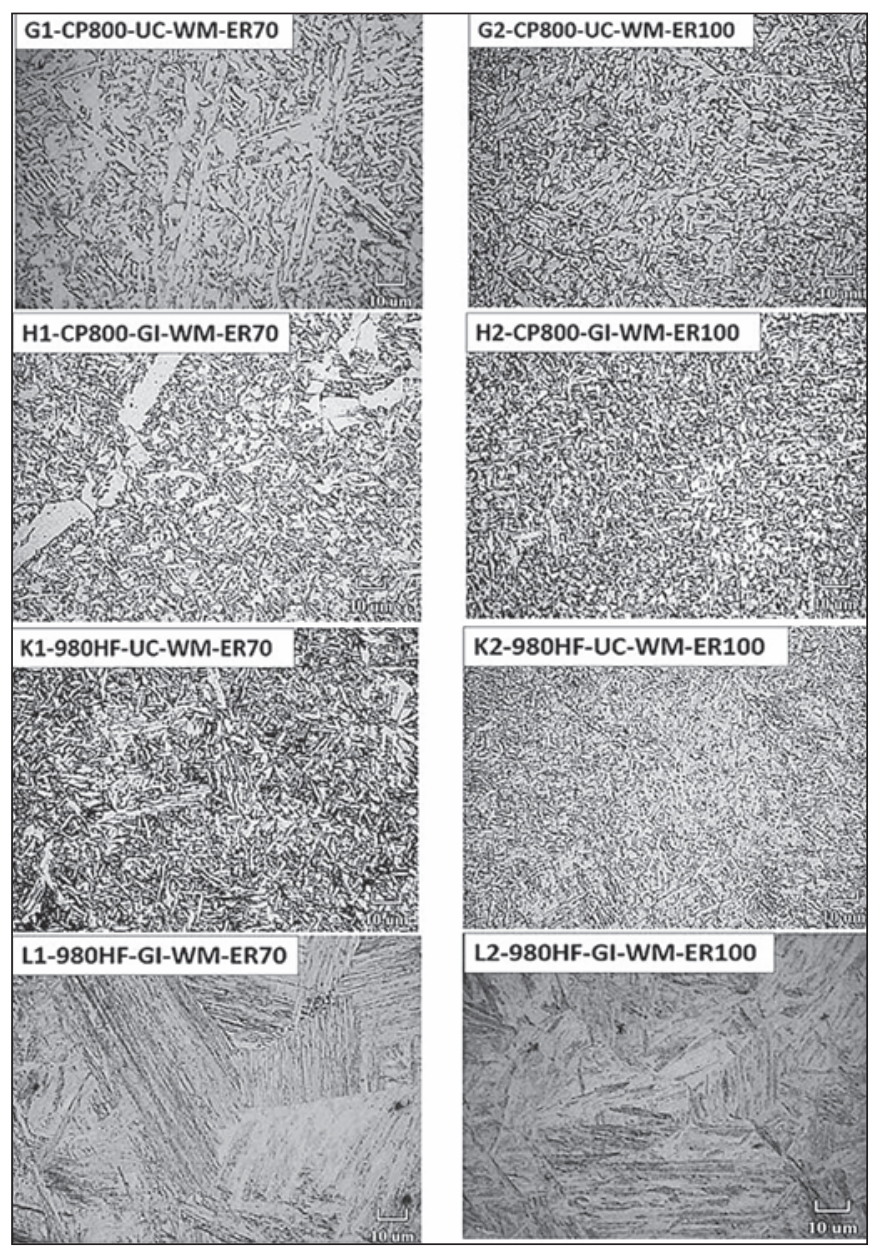

Fig. 6-Optical micrographs show the CGHAZ microstructure for each condition.
Table 4-Average Hardness Values Measures in Zones across Welds for Butt Joints

\begin{tabular}{ccccccccc} 
Material & \multicolumn{4}{c}{ CP800 } & \multicolumn{4}{c}{$980 \mathrm{HF}$} \\
& Uncoated & Gl Coated & \multicolumn{3}{c}{ Uncoated } & Gl Coated \\
\hline Filler Metal & 70 S & 1005 & $70 S$ & $100 S$ & 705 & $100 S$ & 705 & $100 S$ \\
Base Metal & 255 & \multicolumn{2}{c}{248} & 305 & 310 \\
SCHAZ & 230 & 245 & 235 & 235 & 315 & 330 & 340 & 360 \\
CGHAZ & 260 & 270 & 250 & 245 & 460 & 500 & 500 & 480 \\
Fusion Zone & 225 & 248 & 230 & 275 & 310 & 350 & 360 & 430 \\
\hline
\end{tabular}

\section{Tensile Testing for Butt Joint Configuration}

Tensile testing was performed for all butt joints. The results along with the DIC strain maps are shown in Fig. 8. The tensile strength for all joints met or exceeded the base material strength. The ultimate tensile strength (UTS) of the welds in uncoated CP800 was $900 \mathrm{MPa}$ regardless of the welding wire used (see Fig. 8). This is not surprising as both welds had similar HAZ microstructures (Fig. 6, G1 and G2) and both failed in the HAZ. The UTS of the coated CP800 was influenced by filler material where the welds made with the ER70S-6 had a strength of $850 \mathrm{MPa}$, and the welds made 


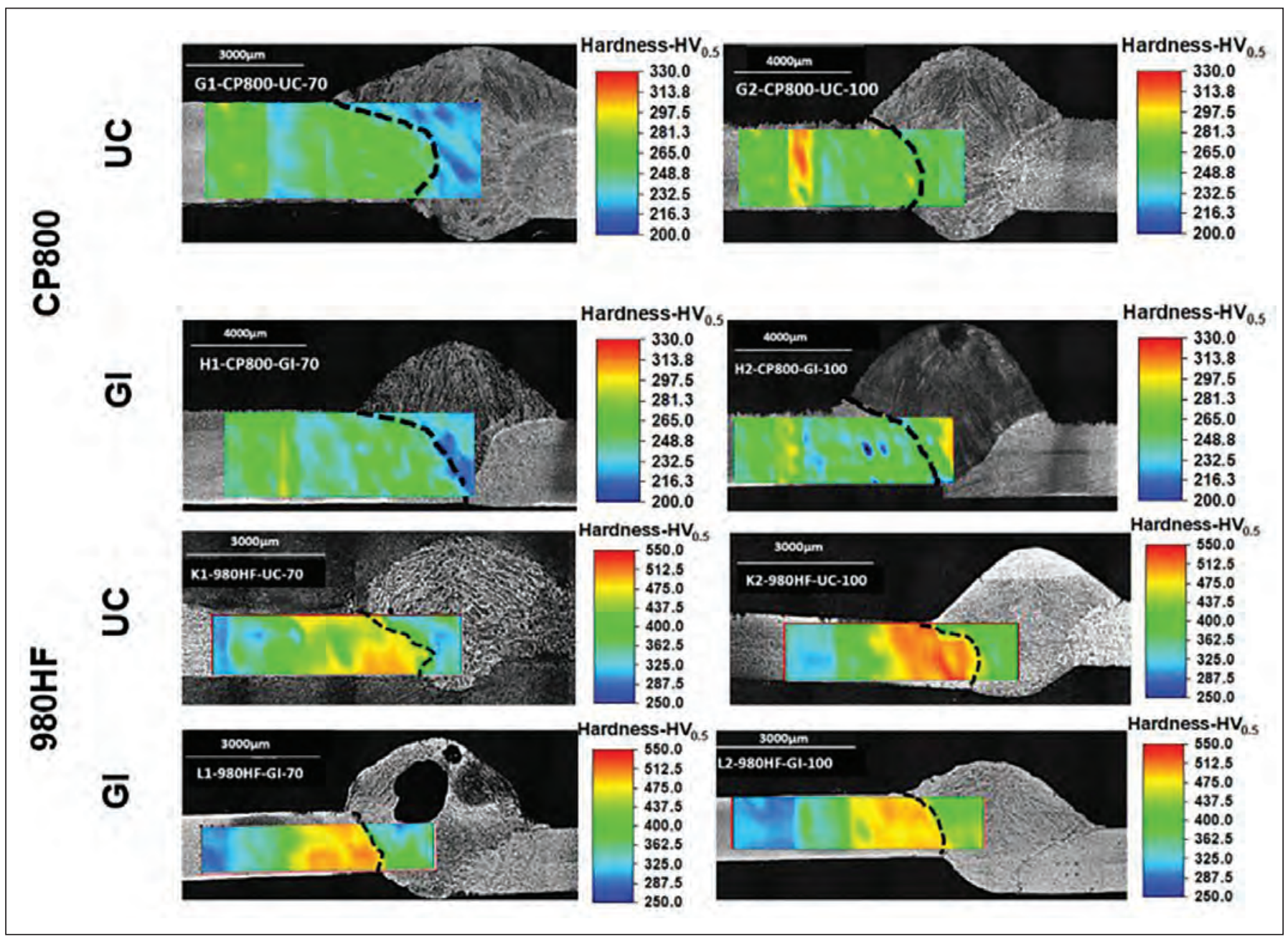

Fig. 7- Hardness maps for the butt joints.

with the ER100S-6 welding wire had a strength of $970 \mathrm{MPa}$. The influence of the welding wire, in this case, may be explained by examining both the strain maps and the microstructures of the welds. When the GI-coated material welded with the low-strength welding wire was pulled, high strain occurred adjacent to the FZ, therefore the mechanical properties of the FZ influenced thinning (see Fig. 8). Also, some pores were observed on the fracture surface of the weld made using the low-strength welding wire, which explains the drop in the strength of the weld. However, when the high-strength welding wire was used, thinning in the area adjacent to the $\mathrm{FZ}$ was restrained, shifting thinning to the harder area further away from the FZ (Fig. 7), increasing the joint strength. The effect of the coating on the tensile strength can be seen in Fig. 8. The coated material exhibited a higher tensile strength compared to the uncoated material when the same filler material was used. It should be noted that there was no improvement in the tensile strength when the high-strength welding wire was used.

All 980HF butt joints exceeded the minimum tensile strength of the base material seen in Table 2. From the DIC strain maps and strain distribution, the maximum local strain was measured in the HAZ on both sides with a maximum value of $10 \%$ for coated and uncoated welds (Fig. 9), although it is interesting to note that in all cases the hardness of this zone was higher than that of the FZ (Fig. 7). The higher strain in the harder HAZ may be due to the larger material thickness (due to reinforcement) of the FZ. Interestingly, the coated material displayed slightly higher strength values; this may be due to the higher carbon equivalent of this material (0.644), as shown in Table 1, which would have contributed to the higher hardness of this zone (see Fig. 7 and Table 4). It should be noted that in the case of the $980 \mathrm{HF}$ welding wire, strength did not significantly increase the strength of the joint. Unlike the case of the CP800, increasing FZ hardness did not shift failure in the butt joint away from lower-strength areas of the weld. Also, internal porosity was observed in the $980 \mathrm{HF}$ coated welds when low-strength welding wire was used in the weld. The porosity reduced the peak strength and total strain by $2 \%$ (see Fig. 9).

The summary of the measured butt joint strength is presented in the bar charts shown in Fig. 10. Using highstrength welding wire did not increase the global strength of the joint, as strain concentration in the softened HAZ determined the global stress-strain behavior. However, the porosity and lack of fusion in some of the coated sheet welds led to a decrease in the butt joint strength and ductility when 


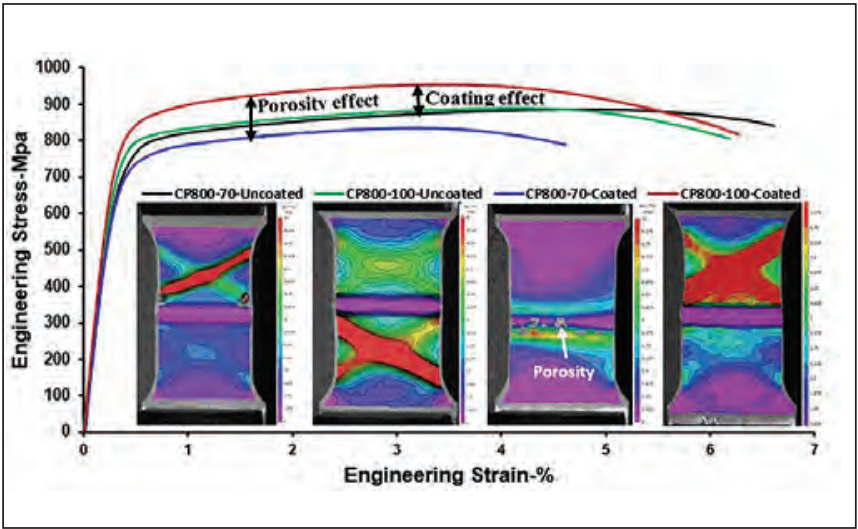

Fig. 8 - Stress-strain curves along with DIC strain maps for CP800 butt joint welds.

A

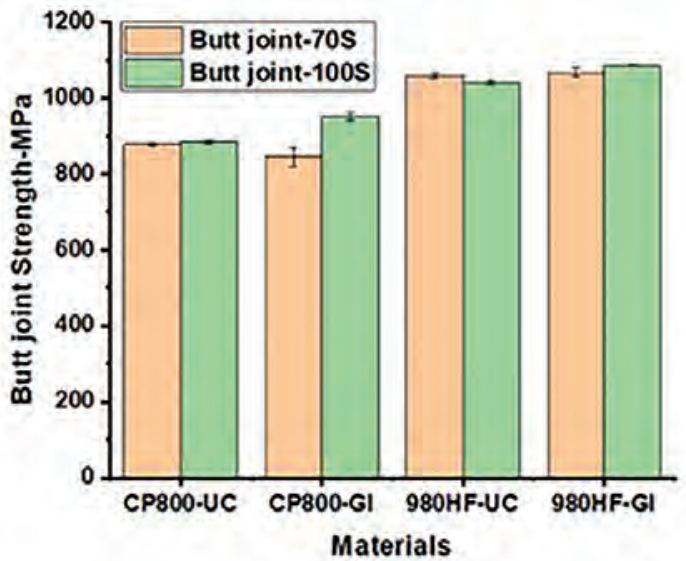

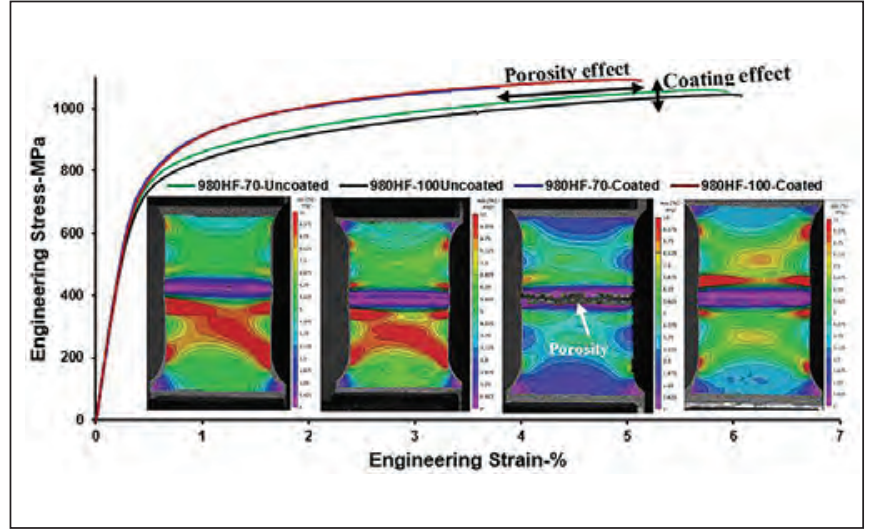

Fig. 9 - Stress-strain curves along with DIC strain maps for 980HF butt joint welds.

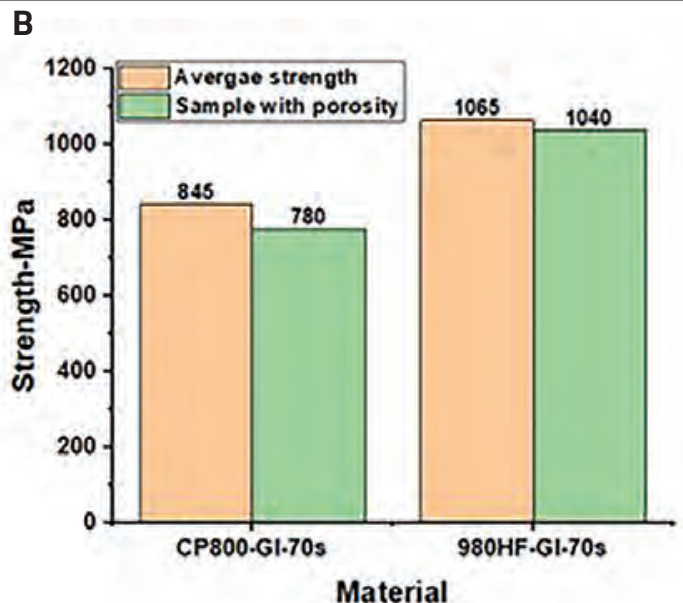

Fig. 10 - Bar charts compare the peak tensile strength values. A - All butt joints produced using different filler metals; $B$ - the effect of porosity on joint performance.

Table 5 - The Average Hardness Data Measured for Each Material across the Welds for Lap Joints

\begin{tabular}{|c|c|c|c|c|}
\hline \multirow[t]{2}{*}{ Material } & \multicolumn{2}{|c|}{ СР800 } & \multicolumn{2}{|c|}{ 980HF } \\
\hline & Uncoated & GI Coated & Uncoated & Gl Coated \\
\hline Filler Metal & 1005 & 70s 100s & 705 100s & 70s 1005 \\
\hline Base Metal & 255 & 248 & 305 & 315 \\
\hline SCHAZ & $270 \quad 265$ & $245 \quad 248$ & $275 \quad 277$ & $300 \quad 275$ \\
\hline CGHAZ & 305 & $260 \quad 270$ & 470485 & 550485 \\
\hline Fusion Zone & 255 & $225 \quad 237$ & 285295 & 295300 \\
\hline
\end{tabular}

low-strength welding wire was used. For example, the strength decreased by $8 \%$ for CP800-GI-70 and $2 \%$ for $980 \mathrm{HF}-\mathrm{GI}-70$. Note that the average strength reported in Fig. 10A included the samples that showed welding defects.

\section{Macrostructure for Lap Joint Welds}

All the lap joint welds were free of porosity, regardless of whether the base material was GI coated or uncoated (Fig. 11). It should be noted that some of the joints presented an inconsistent gap between the sheets, such as in samples $C 2$, D2, and E2, which may affect the joint performance. Howev- er, comparing the strength values to the recommended values in the standard procedure showed these values are acceptable. It was seen that although some samples had large gaps, the measured joint strength and joint efficiency were high. Therefore, although it is acknowledged that a gap will increase stress during testing, it seems that the presence of a gap will not necessarily degrade joint strength. In addition, high heat was used to weld the GI-coated materials to allow zinc vapor bubbles to escape and prevent porosity, as suggested in previous literature (Refs. 15, 17). This had the effect of increasing joint penetration, as shown in Fig. 11, which was more visible in 980HF-GI-coated welds.

\section{Hardness Profiles for Welds Made in the Lap Joint Configuration}

Hardness profiles were measured across each lap joint. These were constructed by averaging the results of two hardness profiles and are reported in Fig. 12. The CP800 weld showed slight variation in the hardness profiles, and the FZ hardness was comparable or slightly softer than the base material hardness (Fig. 12). The base material hardness for uncoated CP800 sheets was $255 \mathrm{HV}_{0.5}$, while the GIcoated sheets were slightly softer $\left(248 \mathrm{HV}_{0.5}\right)$ due to the slight 


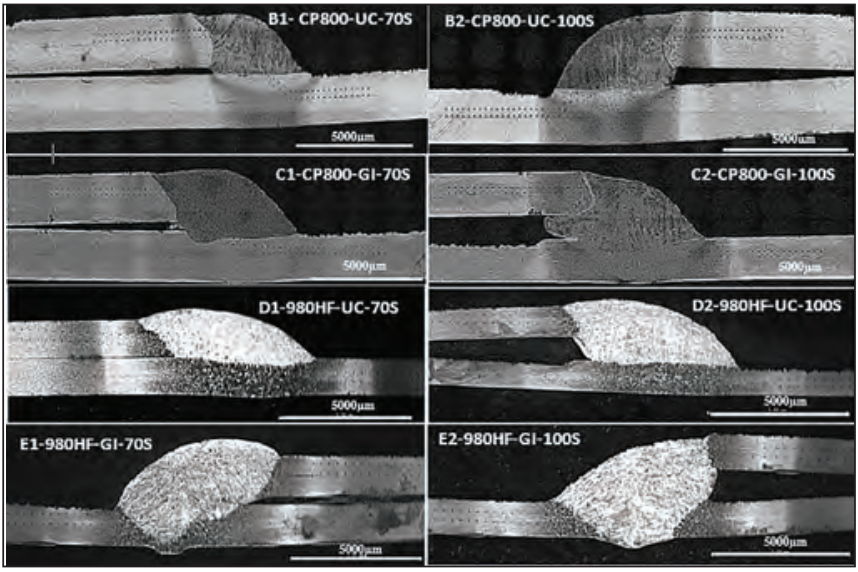

Fig. 11 - The cross section shows the macrostructure for lap joints.

variation between the carbon equivalent of the two materials $\left(C_{\mathrm{eq}}\right.$ is 0.345 for the CP800 uncoated material vs. 0.337 for the CP800 GI-coated material). When high-strength welding wire was used (with its associated change in welding parameters), the hardness of the FZ was similar to that of the base material. It should be noted that the HAZ near the BM SCHAZ showed hardening behavior. This is due to the transformation of preexisting carbides found within the bainite structure and usually occurs at temperatures around $500^{\circ} \mathrm{C}$ (Ref. 27). It should also be noted that softening was not seen in the HAZ of the CP800 lap joint, unlike the observations from the butt joints. The 980HF lap joint hardness profiles are shown in Fig. 12; the $\mathrm{BM}$ hardness for $980 \mathrm{HF}$ is 305 and $315 \mathrm{HV}_{0.5}$ for uncoated and GI-coated sheets, respectively. The FZ hardness of the $980 \mathrm{HF}$ joint welded using both consumables (low-strength and high-strength welding wires) was slightly softer than that of the $980 \mathrm{HF}$ base material hardness (see Table 5 for more details). The hardness values of 285 to $300 \mathrm{HV}_{0.5}$ in the $\mathrm{FZ}$ were due to the change in the welding parameters (lower travel speed and higher welding wire feed speed see Table 3). Using a high-strength welding wire slightly improved the weld metal hardness for both coated and uncoated welds, but the hardness values undermatched the BM hardness. The hardness of the CGHAZ reached up to 550 $\mathrm{HV}_{0.5}$ for the $980 \mathrm{HF}-\mathrm{GI}$-coated plate welded using the lowstrength welding wire. This was due to the formation of a fully martensitic microstructure, as shown in Fig. 6.

The hardness mismatch between the weld metal/HAZ in

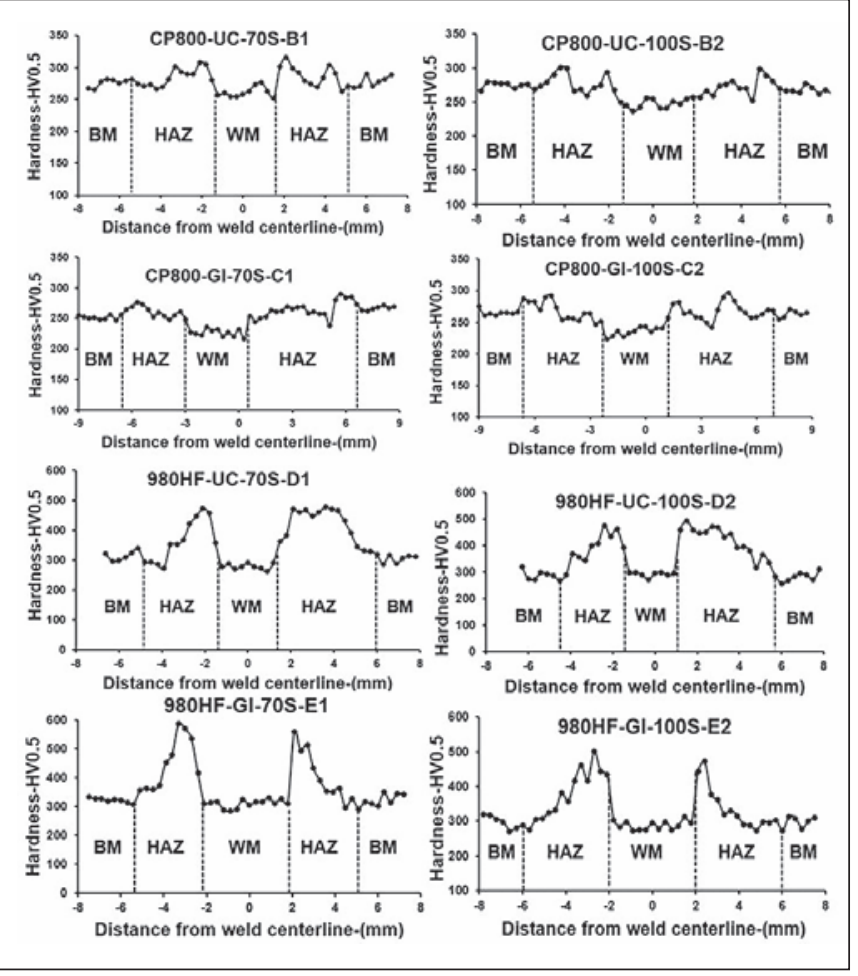

Fig. 12 - Hardness profiles for the lap joint configurations.

the $980 \mathrm{HF}$ welds was very high (300 $\left.\mathrm{HV}_{0.5} / 500 \mathrm{HV}_{0.5}\right)$, which promoted failure at the FZ/HAZ interface. Softening was also seen in the subcritical HAZ near the transition to the $\mathrm{BM}$ due to the martensite from the BM tempering. However, due to the hardness mismatch and a high-stress concentration that occurred near the weld interface, failure did not occur in the softened HAZ. Similar behavior was reported in previous literature (Ref. 10). The summary of the hardness results for each zone/material is shown in Table 5.

\section{Tensile Testing for Lap Joint Configuration}

The lap joints were prepared and tested using a tensile frame with a DIC system to map the strain for both materials, similar to the butt joint configuration. To observe the sample rotation and strain distribution on the side view using the DIC system, the tensile frame grips were rotated 90 deg. The stress-extension curves for the CP800 lap shear

Table 6 - The Average Peak Load and Strength with Standard Deviation for Both Weld Configurations Measured by Tensile Test

\begin{tabular}{|c|c|c|c|c|c|c|c|c|}
\hline \multirow{2}{*}{$\begin{array}{c}\text { Material } \\
\text { Configuration }\end{array}$} & \multicolumn{2}{|c|}{ CP800-UC } & \multicolumn{2}{|c|}{ CP800-GI } & \multicolumn{2}{|c|}{ 980HF-UC } & \multicolumn{2}{|c|}{ 980HF-GI } \\
\hline & ER70 & ERIOO & ER70 & ERIOO & ER70 & ERIOO & ER70 & ERIOO \\
\hline Butt Joint Peak Load-kN & $82 \pm 0.4$ & $83 \pm 0.22$ & $78 \pm 2.9$ & $82 \pm 0.04$ & $49 \pm 0.35$ & $49 \pm 0.23$ & $50.2 \pm 0.05$ & $51 \pm 0.16$ \\
\hline Butt Joint Strength-MPa & $878 \pm 5$ & $884 \pm 4$ & $802 \pm 24$ & $952 \pm 10$ & $1059 \pm 6$ & $1041 \pm 5$ & $1067 \pm 11$ & $1087 \pm 3$ \\
\hline Lap Joint Peak Load-kN & $85 \pm 2.7$ & $95.5 \pm 0.2$ & $81.2 \pm 0.8$ & $94.3 \pm 1.1$ & $51.9 \pm 1.4$ & $57.9 \pm 1.9$ & $56.9 \pm 0.2$ & $60.2 \pm 0.6$ \\
\hline Lap Joint Strength-MPa & $707 \pm 41$ & $792 \pm 0.5$ & $666 \pm 5$ & $765 \pm 9$ & $885 \pm 18$ & $972 \pm 24$ & $965 \pm 6.5$ & $1033 \pm 12$ \\
\hline
\end{tabular}




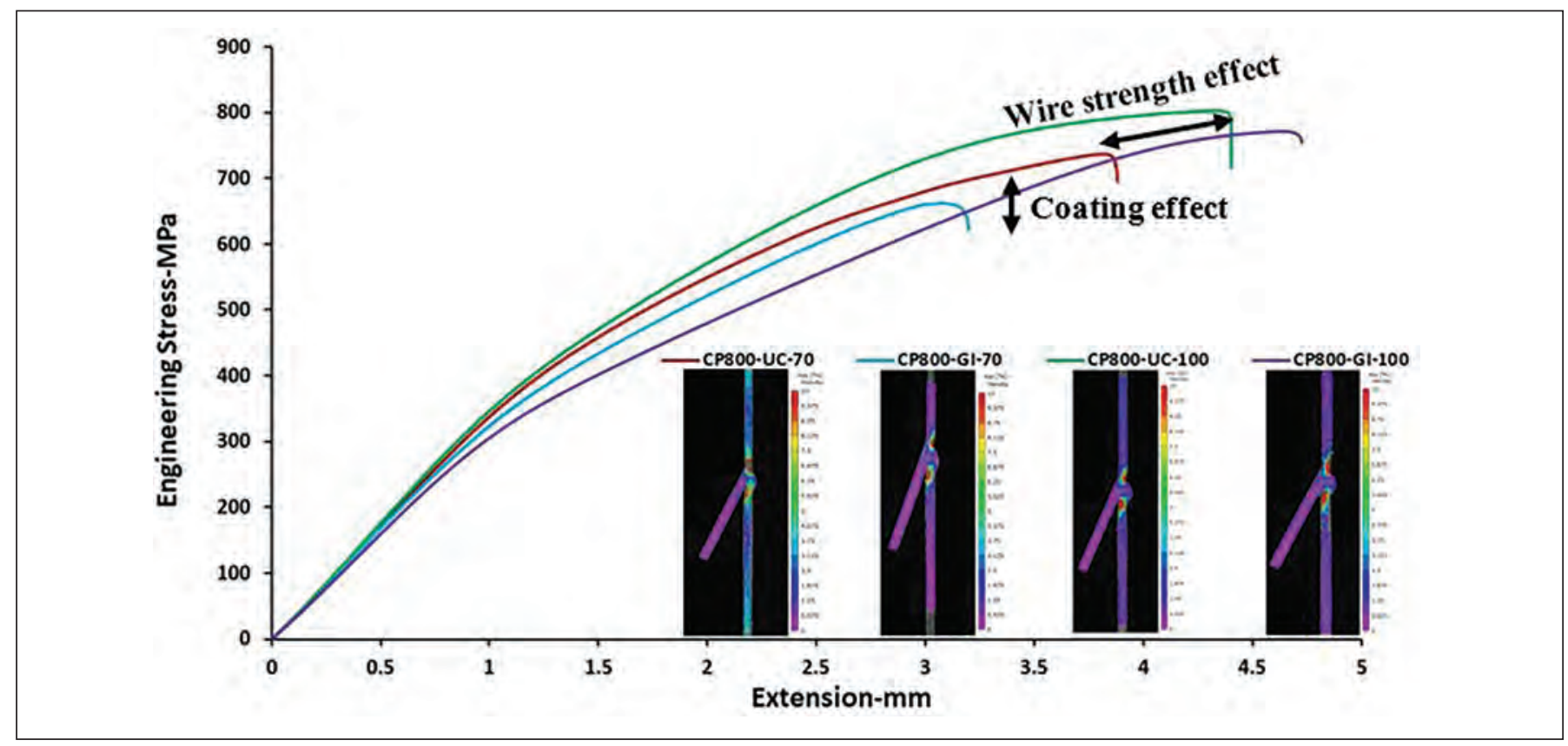

Fig. 13 - Stress-extension curve for CP800 lap shear tests along with the last DIC frame of strain distribution.

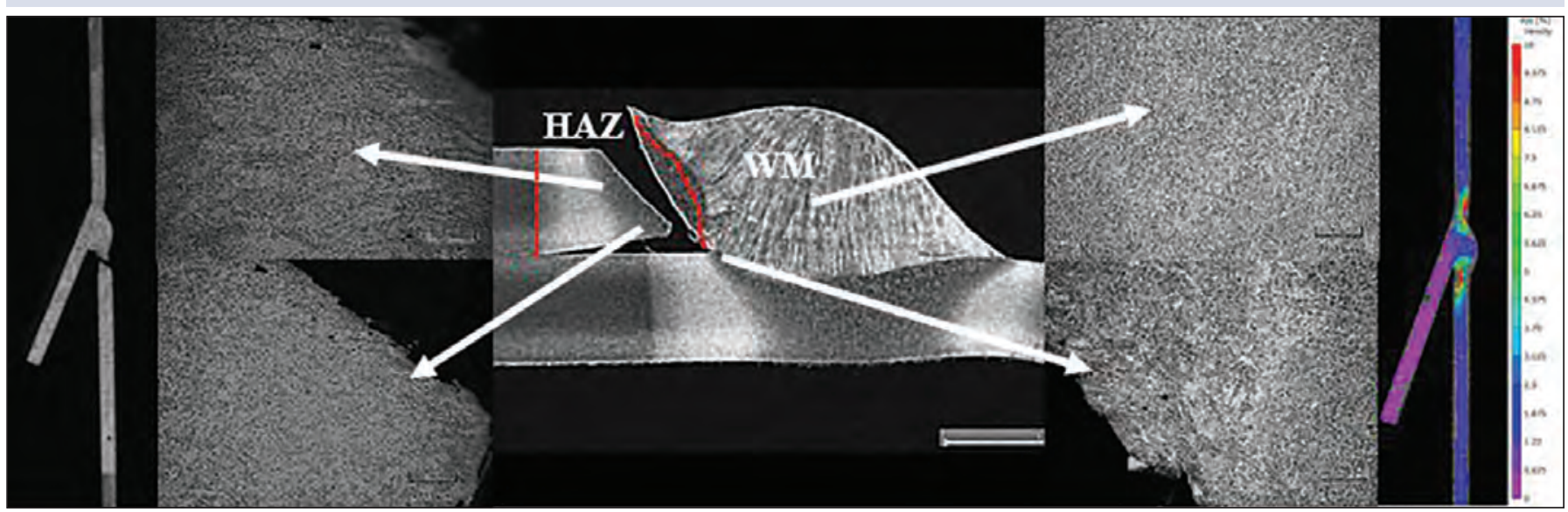

Fig. 14 - Micrographs show the fracture location for the CP800 weld in the HAZ.

tests are shown in Fig. 13. It should be noted that using a high-strength welding wire improved the peak strength and ductility of CP800 slightly. In addition, the rotation in the CP800 was higher (20 to $22 \mathrm{deg}$ ), which imposed higher bending stress, compared to the 980HF lap joint rotation (10 to $15 \mathrm{deg}$ ).

All samples showed strain localization in the HAZ. The strain maps for the uncoated CP800 welds showed that the weld failure occurred when local strain in the HAZ reached about $10 \%$ engineering strain; however, failure occurred near the weld interface in the FZ/HAZ boundary for the CP800 welds, as shown in Fig. 14. This is in agreement with previous work from Biro et al. (Ref. 10), who showed that when the BM had moderate to high hardness and the weld had low hardness, the joint failed in the FZ/HAZ boundary.

The stress-extension curves and DIC strain maps for 980HF welds are shown in Fig. 15. In this weld, strain localized in the HAZ, and the maximum local strain was only $5 \%$. In all of the $980 \mathrm{HF}$ lap joints, the fracture occurred in the FZ near the weld interface (see Fig. 16) even though the FZ did not contain any pores or other defects. This behavior may be explained by the hardness profiles, which showed that the FZ had a lower hardness of about $300 \mathrm{HV}_{0.5}$ compared to the surrounding $\mathrm{HAZ}\left(490 \mathrm{HV}_{0.5}\right)$. This sharp transition in the hardness profile due to the heterogeneity of the microstructure leads to deformation restriction in the $\mathrm{FZ}$ and rotation near the FZ/HAZ boundary, so the failure occurs in the weak area: the FZ. The strain map did not show any effect of coating on the strain distribution. In terms of the coating effect on the strength of the joint, no clear effect was observed on weld strength. While using a high-strength welding wire did not improve the joint strength, however, the ductility of the joint improved when a high-strength welding wire was used. Finally, the low angle of rotation (10 to $15 \mathrm{deg}$ ) for the $980 \mathrm{HF}$ weld samples could be attributed to the high hardness of the HAZ, which restricts the deformation in the FZ.

When the strength of all of the tested joints were compared to each other, it was clear that the butt joints exhibit- 


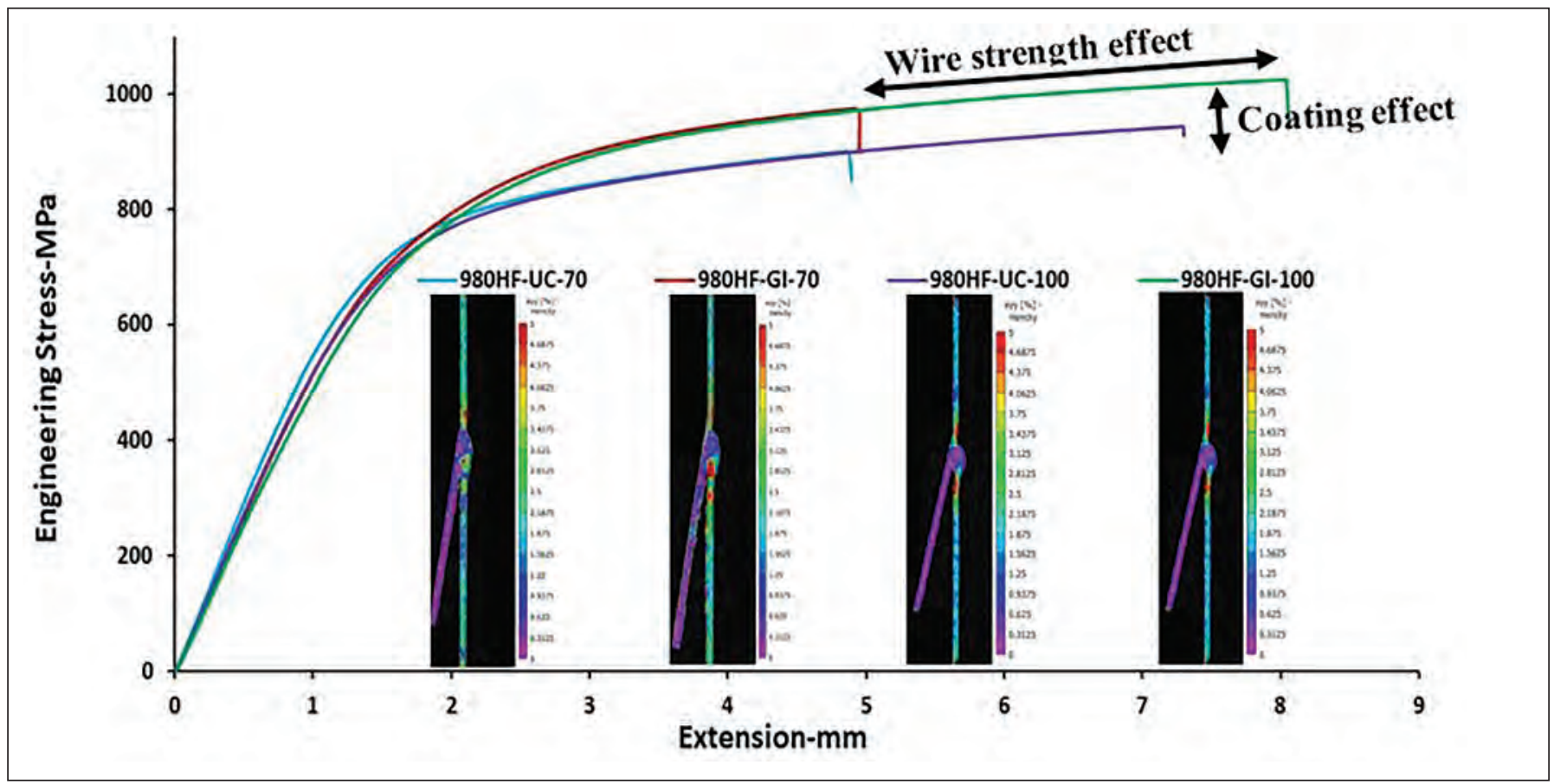

Fig. 15 - Stress-extension curve for 980HF lap shear tests along with the last DIC frame of strain distribution.
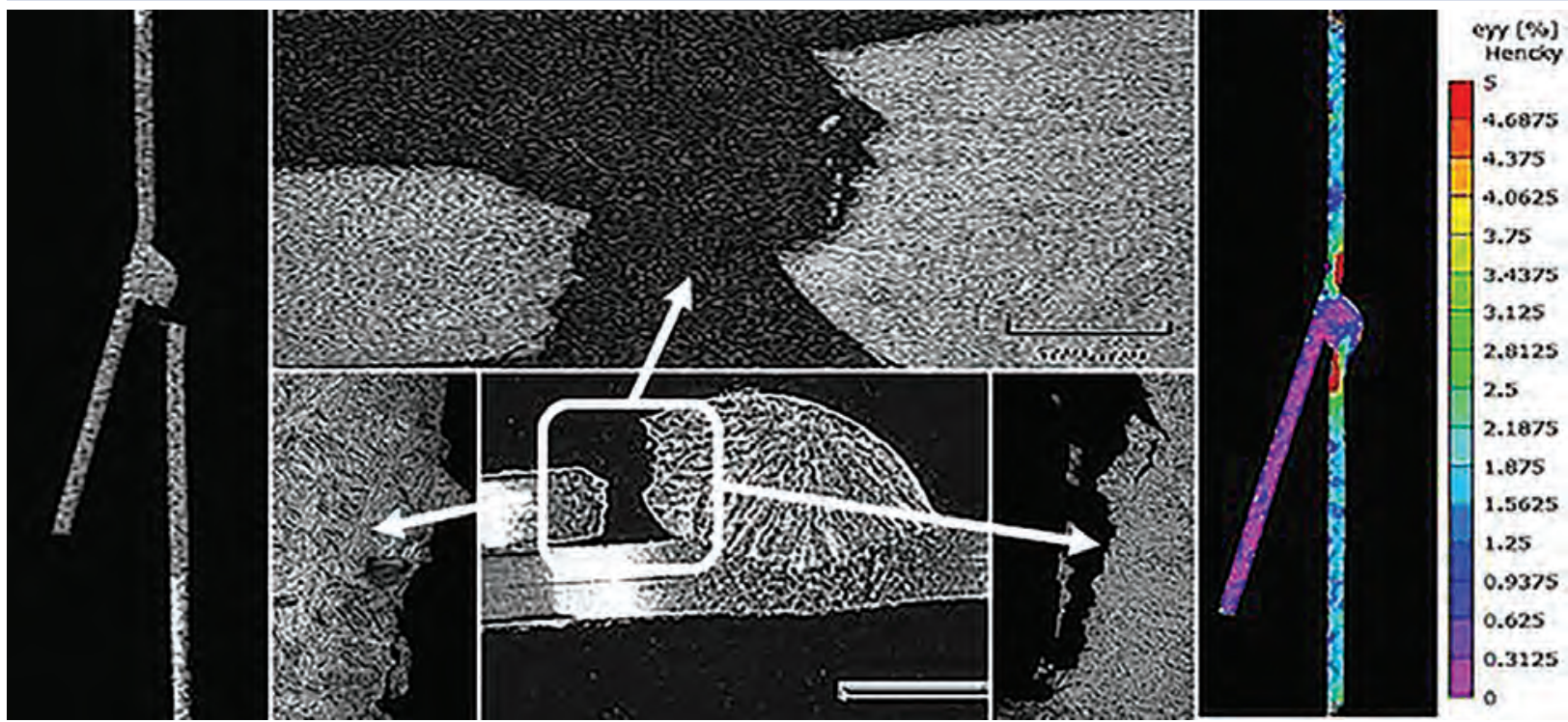

Fig. 16 - Micrographs show the failure location for the 980HF weld in the weld zone.

ed a higher strength than the lap joints, as shown in Fig. 17. In general, using a high-strength consumable (ER-100S-6) slightly improved the joint strength in the butt joint configuration while it significantly improved the joint strength in the lap joint configuration,

Figure 18 shows the failure location for each configuration. It was also noted that the failure of the butt joint in the CP800 welds exhibited the traditional failure behavior through the BM where the failure was oriented 45 deg to the tensile force. Failure occurred on the maximum shear plane, while the $980 \mathrm{HF}$ failure followed a straight path through the HAZ-BM boundary. The lap joint failure of the CP800 welds for all samples was through the HAZ, while the 980HF lap joint welds failed in the boundary between the HAZ-FZ due to the excessive strength mismatch between these two zones, as shown in the hardness profiles in Fig. 12.

Table 6 summarizes the peak load in $\mathrm{kN}$ for both configurations when tested in two different configurations. To calculate the stresses, the peak load value was divided by the crosssection area. It should be noted that at least three mechanical tests were conducted for each condition. The load needed to break the $980 \mathrm{HF}$ samples was lower due to the smaller thickness of the sheets compared to the CP800 samples.

To understand the effect of coating and welding wire strength, the weld strength was processed to visualize how each factor affects lap joint mechanical performance. In the 


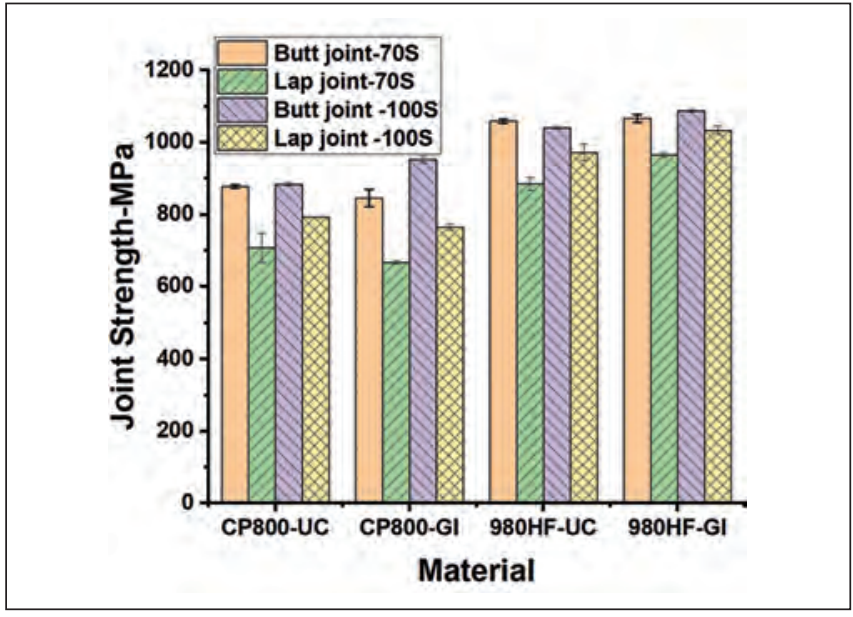

Fig. 17 - Bar chart compares the peak tensile strength values for the tested materials in both butt and lap joint configurations using different filler materials.

case of the CP800 steel, the joint strength was higher for the uncoated materials regardless of the welding wire used Fig. 19. Conversely, in the case of the $980 \mathrm{HF}$, the strength was higher for the GI-coated steel regardless of the welding wire strength. It is thought this behavior may be explained by the welding parameters used to weld the CP800, where higher heat input was used to weld the GI-coated steel. This would have resulted in lower cooling rates and a lower hardness value (which may be seen in the hardness profiles in Fig. 12). Also, the hardness mismatch between the weld/HAZ was higher for the $980 \mathrm{HF}$ welds, which would promote failure in the $\mathrm{FZ}$ and lead to a drop in the peak strength compared to the base material.

Welds made in the butt and lap joint configurations had different characteristic strengths. This is not surprising because the welds in the butt joint configuration are only subjected to tensile stresses, and the welds in the lap joint configuration are subjected to both tensile and bending stresses due to the rotation associated with the asymmetrical loading (Ref. 16). Figure 20 shows the effect of the welding wire strength on the lap joint strength. When lap joint strength results are compared to the BM strength, the tensile strength of the lap joints always undermatches the base material strength except in the 980HF-GI-condition weld using a high-strength welding wire (ER100S). In general, using a high-strength welding wire improves the lap joint strength by approximately $10 \%$ in all cases.

Surface coating and filler type also did not seem to affect the difference between the strength of the two joint types. Therefore, it is believed that this difference was due to geometric attributes alone and further work should be done to determine how changing tensile geometry affects joint strength, as these values will be used to model the part strength. The DIC strain maps for the lap joint showed the free end rotation very clearly with the plastic strain value reaching up to $1 \%$, which could be used in future studies to find the unaccounted bending stress associated with the lap shear sample rotation. Using the lower strengths of lap shear joints could result in overly conservative results. Figure 21 compares the lap and butt joint peak strength with

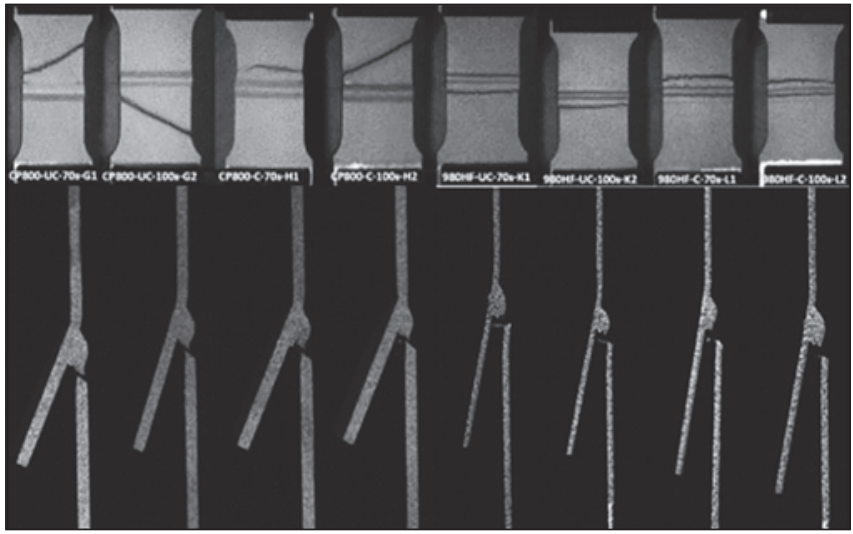

Fig. 18 - Failure location for each configuration.

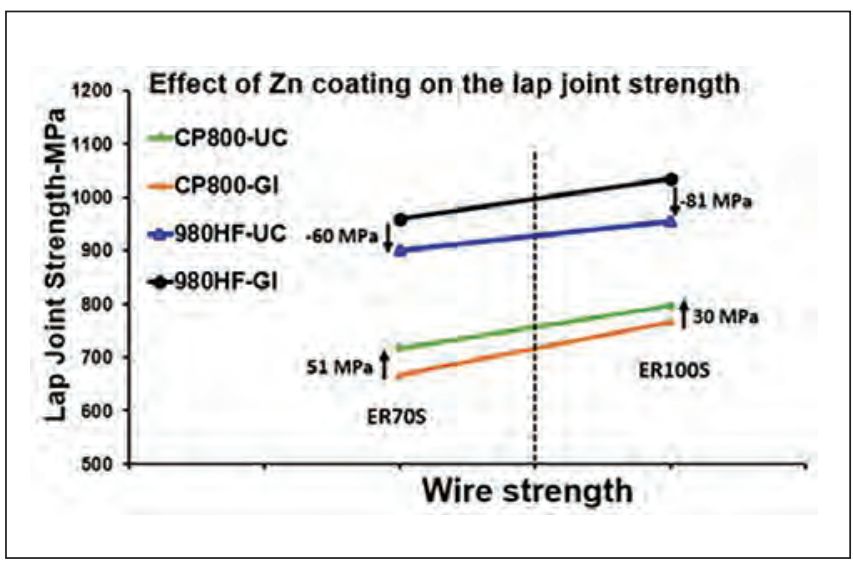

Fig. 19 - Zinc coating effect on the lap joint strength.

the base material strength. The butt joint overmatched the base material in all cases for both materials while the lap joint undermatched the base material except in the $980 \mathrm{HF}$ GI condition. In addition, the butt joint strength exceeded the lap joint strength by $20 \%$ for welds in CP800-UC and $15 \%$ for welds in $980 \mathrm{HF}-\mathrm{UC}$ when welded using a lowstrength welding wire - Fig. 21A. When welded using a high-strength welding wire, the strength difference between the butt and lap joint was $12 \%$ for the CP800-UC and $8.5 \%$ for $980 \mathrm{HF}-U \mathrm{C}$ - Fig. 21C. The GI-coated-material welds showed a similar trend when welded with a low-strength welding wire. The difference between the butt and lap joint was $22 \%$ for the CP800 GI and 10\% for the 980HF-GI (Fig. 21B). When a higher-strength welding wire was used, the difference between butt and lap joint strength was $21 \%$ for the CP800 GI while it reduced to $5.5 \%$ for the $980 \mathrm{HF}-\mathrm{GI}$, as shown in Fig. 21D.

\section{Conclusion}

This work focused on the weldability of AHSS (CP800 and $980 \mathrm{HF}$ ) using the GMAW process. The materials investigated in this project were in both uncoated and GI-coated conditions. The welds were performed using two different filler materials: low-strength filler (ER70S-6) and highstrength filler (ER100S-6). The following conclusions can be drawn from this study: 

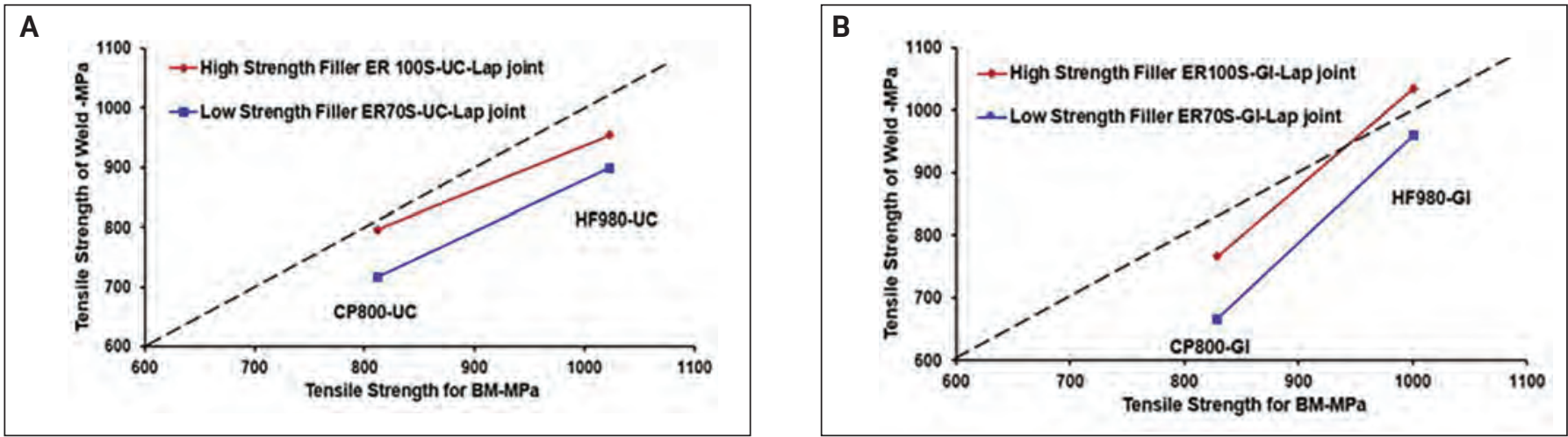

Fig. 20 - Comparison between lap joint strength and base material strength when different filler materials are used in: A Uncoated materials; B - galvanized materials.
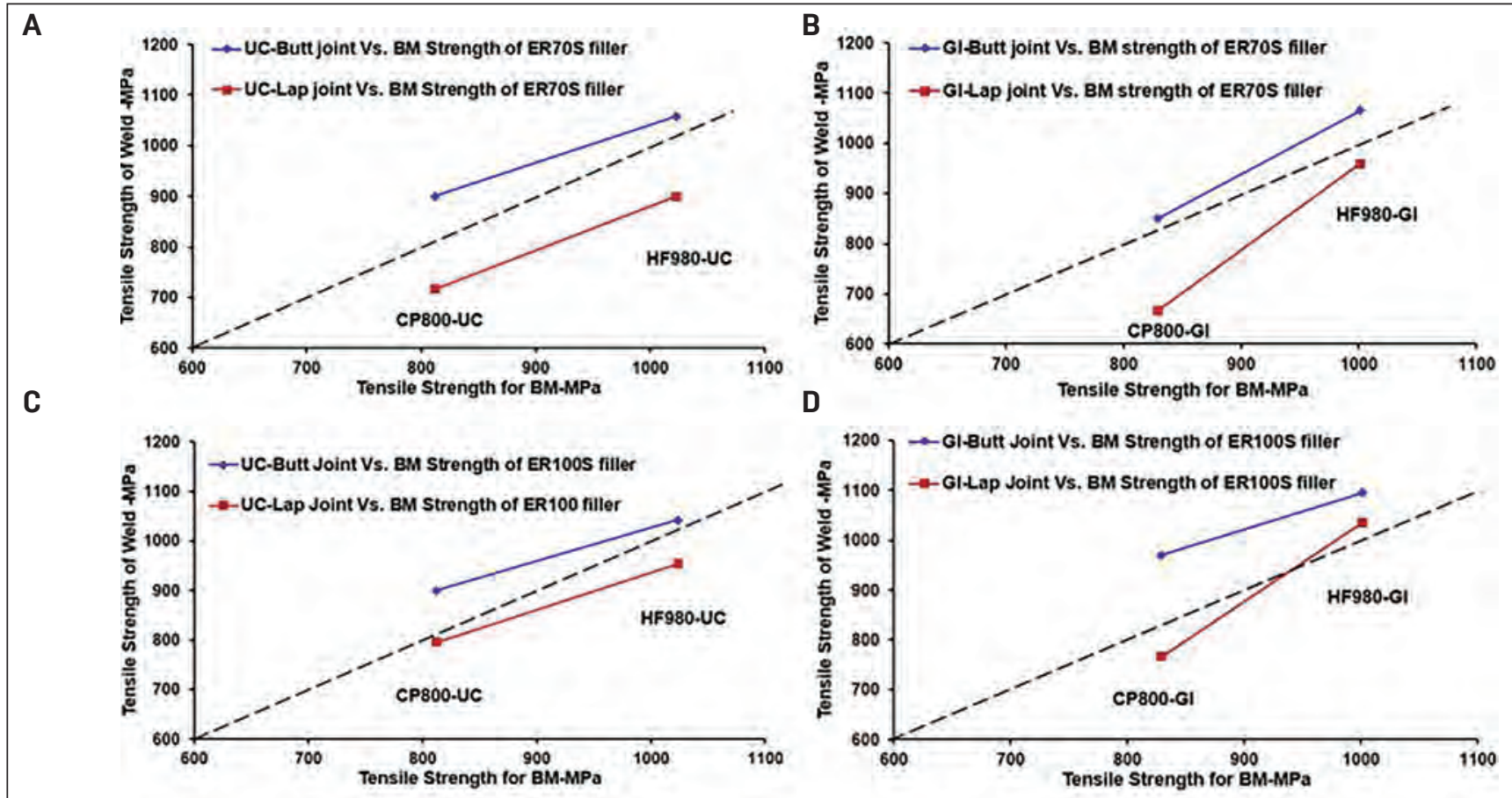

Fig. 21 - Comparison between butt and lap joint strength and base material strength: A - Lower-strength welding wire used without coating; B - lower-strength welding wire used with coating; $C$ - high-strength welding wire used without coating; $D$ - highstrength welding wire used with coating.

1) Material and filler metal effect. The weld strength increases as the material strength increases in both butt and lap joint configurations. However, the increase in the lap joint when a high-strength welding wire is used is higher than the increase in the butt joint strength.

The sharp hardness transition between the CGHAZ and the FZ in the $980 \mathrm{HF}$ welds led to a failure occurring in the FZ. More work is needed to optimize the welding parameters for high-strength material.

2) Zinc coating effect. No clear effect of coating was observed on weld strength. Weld strength is more influenced by metal composition. For example, the $980 \mathrm{HF}$ coated material showed better performance in terms of joint strength compared to the uncoated material.

The porosity present in the FZ of some butt welds in the GI-coated material welded with a low-strength welding wire led to the decrease in average strength. The CP800 welds showed an $8 \%(70 \mathrm{MPa})$ reduction in strength compared to the uncoated materials. A $2 \%(25 \mathrm{MPa})$ drop was seen in the average strength of the $980 \mathrm{HF}$ butt weld samples due to porosity.

No porosity was observed in the lap joint welds. More work is needed to understand how porosity affects joint strength.

3) Joint configuration effect. Joints welded in a butt joint configuration were stronger than those welded in a lap joint configuration and generally overmatched the BM strength.

- Butt joint strength exceeded lap joint strength by $20 \%$ for welds in CP800-UC and 15\% for welds in 980HF-UC when welded using a low-strength welding wire.

-When welded using a high-strength welding wire, the 
strength difference between the lap and butt joint was $12 \%$ for the CP800-UC and 8.5\% for 980HF-UC.

- When a low-strength welding wire was used to join the GI-coated steel, the butt joint strength exceeded the lap joint strength by $22 \%$ for CP800 and $10 \%$ for $980 \mathrm{HF}$.

- Increasing the welding wire strength led to an improvement in the lap joint strength for the 980HF-GI material. The difference between the butt and lap joint decreased from $10 \%$ to $5 \%$.

- It is believed that there is an interaction between welding wire strength and rotation, where increased FZ strength prevents rotation during shear testing, thereby reducing the bending stress and increasing the overall joint strength.

- Due to the prevalence of gaps and their known influence on weld quality, a sensitivity analysis should be done using these AHSS.

4) Sample rotation. The authors believe the lower strength of the lap joint is due to the unaccounted bending stress because of the sample rotation during the tensile test. Future work will focus on developing a new test methodology to prevent sample rotation during the lap shear test.

\section{Acknowledgments}

The authors would like to thank the Natural Sciences and Engineering Research Council (NSERC) of Canada for the financial support of this project through the Engage program. The authors would also like to acknowledge Martinrea International U.S. Inc. for supplying materials and carrying out the welding work.

\section{References}

1. Tamarelli, C. M. 2011. AHSS 101: The evolving use of advance high strength steel for automotive applications. Technical Paper. Steel Market Development Institute, p. 42.

2. National Highway Traffic Safety Administration. Corporate Average Fuel Economy for MY 2017-MY 2025 Passenger Cars and Light Trucks. 2012. Office of Regulatory Analysis and Evaluation Office of Regulatory Analysis.

3. Steel Market Development Institute. 2014. Growth of AHSS Auto Steel. Retreived on February 26, 2019, from web.archive.org/ web/20180802143935/https://www.autosteel.org/research/growthof-ahss

4. Schnatterly, J. 2008. Watching our weight steel content of N. American auto. Paper read at Great Designs in Steel.

5. Kang, M., Jeon, I.-H., Han, H. N., and Kim, A. C. 2018. Tensileshear fracture behavior prediction of high-strength steel laser overlap welds. Metals 8(5): 365. DOI: 10.3390/met8050365

6. Kang, H., Khosrovaneh, A., Amaya, M., Bonnen, J., Shih, H.C., Mane, S., and Link, T. 2011. Application of fatigue life prediction methods for GMAW joints in vehicle structures and frames. SAE 2011 World Congress \& Exhibition. Warrendale, Pa.: SAE International. DOI: 10.4271/2011-01-0192

7. Hernandez, V. H. B. 2010. Effects of martensite tempering on HAZ-softening and tensile properties of resistance spot welded dual-phase steels. PhD diss., University of Waterloo.

8. Yan, B., Lalam, S. H., and Zhu, H. 2005. Performance evaluation of GMAW welds for four advanced high-strength steels. SAE Technical Paper Series. Warrendale, Pa.: SAE International.
9. Burns, T. J. 2010. Weldability of a dual-phase sheet steel by the gas metal arc welding process. Master thesis, University of Waterloo.

10. Biro, E., Jiang, C., and Lyttle, K. 2008. Correlation between failure location and tensile strength of AHSS GMAW lap joint. Paper read at Sheet Metal Welding Conference XIII, Livonia, Mich.

11. Kaplan, A. F. H., Wiklund, G., and Nilsson, T. 2007. The impact of zinc-coating on laser hybrid welding of steel. ICALEO ${ }^{\circledR}$ 2007. Orlando, Fla.: The Laser Institute. DOI: 10.2-351/1. 5061088

12. Yu, J., and Kim, D. 2018. Effects of welding current and torch position parameters on minimizing the weld porosity of zinccoated steel. International Journal of Advanced Manufacturing Technology 95(1): 551-567. DOI: 10.1007/s00170-017-1180-6

13. Narayanan, B. K., Henry, J., Lia, Y.-C., and Galiher, D. 2015. Solutions for welding zinc coated steels. The Lincoln Electic Co., Cleveland, Ohio.

14. SSAB. 2018. Welding of AHSS/UHSS steel: A guide for the automotive industry.

15. Ahsan, M. R. U., Kim, Y. R., Ashiri, R., Cho, Y. J., Jeong, C., and Park, Y. D. 2016. Cold metal transfer (CMT) GMAW of zinccoated steel. Welding Journal 95(4): 120-132.

16. Ono, M., Kabasawa, M., and Omura, M. 1997. Static and fatigue strength of laser-welded lap joints in thin steel sheet. Welding International 6(11): 462-467. DOI: 10.1080/09507119709451995

17. Kapustka, N., Conrardy, C., Babu, S. and Albright, C. 2008. Effect of GMAW process and material conditions on DP 780 and TRIP 780 welds. Welding Journal 87(6): 135-s to 148-s.

18. Seong, W. J. 2019. Prediction and characteristics of angular distortion in multi-layer butt welding. Materials 12(9): 1435. DOI: 10.3390/ma12091435

19. Masubuchi, K. 1980. Analysis of Welded Structures Residual Stresses, Distortion, and Their Consequences. MIT, USA: Pergamon Press.

20. Yurioka, N. 2001. Physical metallurgy of steel weldability. ISIJ International 41(6): 566-570. DOI: 10.2355/isijinternational.41.566

21. American Welding Society. 2005. A5.18/A5.18M, Specification for Carbon Steel Electrodes and Rods for Gas Shielded Arc Welding. Miami, Fla.: American Welding Society.

22. Khosrovaneh, A. 2018. Gas metal arc welding of AHSS. Great Designs in Steel Symposium. Southfield, Mich.

23. Kuo, M. 2019. Gas metal arc welding of advanced high strength steels. Great Designs in Steels.

24. ASTM. 2011. ASTM E3-11, Standard Guide for Preparation of Metallographic Specimens. West Conshohocken, Pa.: ASTM.

25. ASTM. 2017. ASTM E384-17, Standard Test Method for Microindentation Hardness of Materials. West Conshohocken, Pa.: ASTM.

26. Cox, E. P., and Lamba, H. S. 1984. Cluster porosity effects on transverse fillet weld strength. Welding Journal 63(1): 1-s to 7-s.

27. Saha, D. C., Nayak, S. S., Biro, E., Gerlich, A., and Zhou, Y. 2014. Mechanism of secondary hardening in rapid tempering of dual-phase steel. Metallurgical and Materials Transactions A 45A(13): 6153-6162. DOI: 10.1007/s11661-014-2591-8
ABDELBASET R. H. MIDAWI (amidawi@uwaterloo.ca) and ELLIOT BIRO are with CAMJ Group, Mechanical and Mechatronic Engineering Department, University of Waterloo, Waterloo, Ontario, Canada. SRINATH KISTAMPALLY is with Martinrea International U.S. Inc., Auburn Hills, Mich. 